\title{
Consideration of eligibility for consultant posts of long-term consultant locums and others in similar situations
}

\section{The problem}

Because of the manpower imbalance between registrar and senior registrar grades which existed for some years, but has recently been corrected, in the late 1980 s and early 1990 s a number of qualified and suitable applicants for higher training were unable to obtain senior registrar posts. Some of these have since undertaken long-term consultant locums and have obtained extensive experience at this level. With the introduction of the new Specialist Register and the legal requirement that appointees to National Health Service consultant posts and similar posts in Ireland are included on the relevant Specialist List, a review mechanism is proposed for indtviduals in this situation. It is also proposed to apply this to a limited number of people who, for a considerable time, have been performing duties equivalent of the level of Consultant elsewhere, for example in the private sector.*

\section{Proposed procedure}

1. Individuals for review under this procedure should be proposed by, and have the support of, the College Regional Adviser for the Region in which they are working at the time of submission, or have worked for most of the time since obtaining the MRCPsych. If the applicant is in a different speciality from the Regional Adviser, then the Regional Adviser must consult the Regional Representative of the speciality in question.

2. A proposal will be made to the Registrar who will seek the advice of the relevant Specialist Advisory Sub-Committee (SAC) of the Joint Committee on Higher Psychiatric Training in a process similar to that currently applied for consultants who are deemed insufficiently trained at the time of appointment. The proposal should be accompanied by a curriculum vitae and a detailed account of the applicant's experience, together with reports obtained by the Regional Adviser from three Fellows or

*Members are reminded that the College has established procedures for those consultants who wish to change specialities. The Joint Committee for Higher Psychiatric Training (JCHPT) will, in such circumstances suggest a tallor-made programme of additional training. Members who wish to receive further details should contact the JCHPT.
Members of the College familiar with the applicant's work in recent years. One of these reports should be from the Regional Representative if the Speciality concerned differs from that of the Regional Adviser.

3. To be eligible for this procedure, an individual should have obtained the MRCPsych, have been working at consultant level for at least five years, and should have had long-term experience in one or a small number of consultant posts. Individuals working at sub-consultant level, e.g. in staff grade or clinical assistant posts, will not be eligible for this procedure, and such individuals should undergo standard higher training in a senior registrar or specialist registrar post. Individuals who have been in long-term consultant locums for less than five years may, after appointment to a senior registrar or specialist registrar post apply to the JCHPT to determine whether any of this time is recognised for training.

4. Criteria to be considered by the SAC will include length of experience in the speciality, nature of that experience and its relevance to equip a fully trained specialist in the speciality, calibre and previous experience of the individual, and other aspects relevant to the individual's circumstances and standards required of trained consultants in the speciality.

5. The SAC will then make recommendations to the Court of Electors. The recommendations may or may not include either eligibility for a consultant post or a recommendation for specifled training either on a part-time or fulltime basis to qualify that person for a Certificate of Completed Specialist Training (CCST) and hence eliglbility for consultant appointment. It is probable that some specified training will be necessary for most applicants. There may be some applicants who are not considered eligible by the relevant SAC for this procedure, in which case appeals should be made to the Court of Electors.

6. Since this is introduced primarily to deal with a temporary situation, these recommendations will remain in effect for 18 months, to be reviewed at the end of that period. This will run from the date letters are sent to Regional Advisers, which occurred in January 1996. 
7. Funding and sessional commitment to training will need to be supported at local level. This is not the responsibility of the Royal College of Psychiatrists.
Revised and Approved by the

Court of Electors

27 February 1996

\section{Letter to the Secretary of State}

The President sent this letter to the Secretary of State during the Winter Meeting of the College in January 1996. Since then we have been encouraged by the Secretary of State's speech to the House of Commons on 20 February, 1996 which addressed some of these issues.

Dear Mr Dorrell: Concern in the Royal College of Psychiatrists with regard to the implementation of Care in the Community has reached unprecedented levels.

You will be aware that the College has consistently supported the Policy, but has regularly communicated concerns to officials and ministers in recent years. For example I wrote to your predecessor two years ago suggesting that no further in-patient psychiatric beds should be closed until additional community facilities were in place.

The problems that there are in delivering a safe psychiatric service in many parts of the country are well known to you, and also that we are far from being able to provide a service of any quality in most places.

As you consider the responses of Commissioners to Mr Malone's letter to them of last August asking about their progress in meeting the ministerial priority for the service, I thought that I should let you know that I am facing mounting pressure to put a very critical motion of the lack of improvement which has been achieved to the College's annual meeting in July which would inevitably become public.

I think it would be more constructive and in the interest of patients if we could collaborate even more actively with your officials during the next few months to try and produce solutions to some of the problems. In our view one of the continuing impediments to change is the apparent lack of knowledge of a number of Chief Executives of the different elements required for a safe and comprehensive psychiatric service.

We are already working together on the serious deficiencies in psychiatric staffing and on defining the 'seriously mentally ill' and have recently reached agreement on improving the training of those doctors who admit patients to hospital under the Mental Health Act.

I look forward to hearing from you in the near future. Perhaps we could have a meeting to discuss the situation.

Fiona CaLdicott

\section{Psychiatric reports for the Parole Board}

\section{Introduction from the President}

Dr John Reed from the Department of Health wrote to the President in July 1995 following a meeting he had had with the Parole Board. The Parole Board has expressed concern to Dr Reed about the quality and usefulness of some of the reports that they receive written by psychiatrists.
The Courts, from time to time, have expressed a similar concern. It is important to note, of course, that reports for Parole Boards are not the same as reports for the Courts, although both will include mental state at the time of offence. The College has received comments that instructions received from the Parole Boards are often not very clear and we shall be relaying these criticisms to the Parole Board. It must be said, however, that the 